\title{
CONTROLE DE MANCHA-ANGULAR UTILIZANDO-SE CALDAS FERTIPROTETORAS EM CULTIVO ORGÂNICO DE FEIJOEIRO IRRIGADO ${ }^{1}$
}

\author{
Wellington Pereira de Carvalho², Alberto Luiz Wanderley ${ }^{3}$, Charles Martins de Oliveira²
}

\section{ABSTRACT \\ CONTROL OF ANGULAR LEAF SPOT BY USING \\ PROTECTIVE MIXTURES IN IRRIGATED COMMON BEAN UNDER ORGANIC CROPPING SYSTEM}

A field experiment was carried out with the Pérola and BRS Valente cultivars, aiming to evaluate the efficiency of protective mixtures, in two spraying periods, for controlling angular leaf spot caused by Phaeoisariopsis griseola in common bean, under organic cropping system, in the dry season and under irrigation. A randomized complete block design, in a $2 \times 4$ factorial scheme, with four replications, was used, in which the first factor was the spraying intervals (15 and 30 days), and the second the protective mixtures (bordeaux, lime sulfur, and a mixture with silicate Rocksil ${ }^{\circledR}$ ) and control without any mixture. To the Pérola cultivar, the bordeaux mixture provided an increase of $17,7 \%$ in grain yield, when compared to the non-sprayed control, reducing significantly the angular leaf spot severity, achieving a control efficiency of $75 \%$, and propitiating a profit of R $\$ 386.40 \mathrm{ha}^{-1}$, when applied at each 15 days. To the BRS Valente cultivar, the bordeaux mixture and lime sulfur provided an increase of $25 \%$ and $21,8 \%$ in grain yield, in comparison to the non-sprayed control, achieving a control efficiency of $62 \%$ and a profit of $\mathrm{R} \$ 573.15 \mathrm{ha}^{-1}$ and $\mathrm{R} \$ 464.10 \mathrm{ha}^{-1}$, respectively, when applied at each 15 days.

KEY-WORDS: Phaeoisariopsis griseola; Phaseolus vulgaris; organic agriculture; bordeaux mixture; lime sulfur.

\section{INTRODUÇÃO}

Nas últimas décadas, o crescimento populacional gerou a necessidade de maior produção de alimentos, que foi conseguida pela intensificação de atividades agrícolas. A expansão da fronteira agrícola, associada à intensificação na utilização dos recursos do meio, ocasionou desequilíbrios e redução da diversidade biológica nos agroecossistemas (Altieri 1999), fatores que intensificaram os problemas de infestação com pragas e doenças. Ainda, a seleção de

\section{RESUMO}

O objetivo deste trabalho foi avaliar a eficácia de caldas fertiprotetoras, em dois intervalos de aplicação, no controle de mancha-angular causada por Phaeoisariopsis griseola, em sistema orgânico de produção, no período de inverno e sob irrigação por aspersão. O experimento foi desenvolvido a campo, com as cultivares de feijoeiro comum (Phaseolus vulgaris L.) Pérola e BRS Valente. Utilizou-se delineamento experimental de blocos ao acaso, em esquema fatorial $2 \times 4$, com quatro repetições, em que o primeiro fator correspondeu aos intervalos de aplicação (15 e 30 dias) e o segundo a caldas fertiprotetoras (bordalesa, sulfocálcica e calda elaborada com silicato Rocksil ${ }^{\mathbb{}}$ ) e testemunha sem controle da doença. Para a cultivar Pérola, apesar de a eficácia de controle da doença ser semelhante à da calda sulfocálcica, somente a calda bordalesa proporcionou acréscimo no rendimento de grãos de 17,7\%, em relação à testemunha, propiciando rentabilidade de $\mathrm{R} \$ 386,40$ por hectare. Para a cultivar BRS Valente, as caldas bordalesa e sulfocálcica, aplicadas quinzenalmente, proporcionaram acréscimo ao rendimento de grãos de $25,0 \%$ e $21,8 \%$, em relação à testemunha, além de apresentarem eficácia de controle de $62 \%$ da mancha-angular, propiciando rentabilidade de $\mathrm{R} \$ 573,15$ e $\mathrm{R} \$ 464,10$ por hectare, respectivamente.

PALAVRAS-CHAVE: Phaeoisariopsis griseola; Phaseolus vulgaris; agricultura orgânica; calda bordalesa; calda sulfocálcica.

cultivares mais produtivas resultou na diminuição da rusticidade natural das plantas, agravando os problemas relacionados às doenças de plantas (Mizubuti \& Maffia 2001).

Nos países em desenvolvimento, estima-se que as doenças de plantas sejam responsáveis por perdas de, aproximadamente, $12 \%$ do total da produção agrícola (Agrios 1997). A necessidade de se reduzir estas perdas levou à adoção, quase que exclusiva, do controle químico de doenças. No Brasil, o aumento demasiado na utilização destes produtos tem gerado

1. Trabalho recebido em maio/2009 e aceito para publicação em nov./2010 (nº registro: PAT 6264/ DOI: 10.5216/pat.v40i4.6264).

2. Embrapa Cerrados, Setor de Pesquisa, Planaltina, DF, Brasil.E-mails: well@cpac.embrapa.br, charles@cpac.embrapa.br.

3. Itec Biotecnologia Agrícola Ltda., Brasília, DF, Brasil.E-mail: itecbiotecnologia@gmail.com. 
preocupação com os problemas ambientais e de saúde pública. Como alternativa, tem sido proposto o estabelecimento de sistemas de produção mais sustentáveis, como o sistema orgânico, no qual os pesticidas não são utilizados. No entanto, o controle de pragas e doenças, neste sistema, representa, ainda, um grande desafio (Maffia \& Mizubuti 1999).

O feijoeiro comum (Phaseolus vulgaris L.) é afetado por considerável número de enfermidades e, entre as doenças fúngicas, que apresentam sintomas na sua parte aérea, se encontra a mancha-angular, causada por Phaeoisariopsis griseola (Sacc.) Ferraris. Esta doença é encontrada, com maior ou menor severidade, em todas as regiões em que esta leguminosa é cultivada (Rava 2002). O patógeno provoca lesões em folhas, vagens, ramos e pecíolos e pode causar grave desfolhamento (Jesus Junior et al. 2003). Sem controle adequado da doença, as perdas podem chegar a 70\% da produção (Sartorato \& Rava 1992), dependendo da susceptibilidade das cultivares e das condições ambientais (Reis-Prado et al. 2006).

Plantas cultivadas em sistemas orgânicos, via de regra, apresentam maior tolerância ao ataque de pragas e doenças, devido a fatores como a utilização de espécies ou variedades mais rústicas e adaptadas ao local de cultivo, tipo de solo selecionado, uso de adubos orgânicos ou adubos minerais de baixa solubilidade (Souza 2006) e maior diversidade biológica no sistema, garantindo desenvolvimento adequado aos inimigos naturais que predam os patógenos de planta. Porém, problemas fitossanitários mais persistentes, como é o caso da doença supracitada, necessitam de tratamento, para viabilizar produções satisfatórias, com qualidade comercial.

O uso de caldas fitoprotetoras, no controle de doenças fúngicas, tem sido preconizado por vários autores, principalmente em hortaliças e fruteiras (Souza 1998, Penteado 2000, Abreu Júnior 2003, Rombaldi et al. 2004, Rodrigues et al. 2006). No entanto, poucos trabalhos científicos avaliaram seu uso nos cultivos de grãos, sendo que, para a cultura do feijoeiro comum, em sistema orgânico, há grande lacuna no conhecimento científico referente à eficácia desta prática, no controle de doenças.

A maioria dos trabalhos sobre o efeito de caldas protetoras, óleos vegetais e extratos de plantas, no controle de doenças, foi desenvolvida in vitro (Schwan-Estrada et al. 2000, Innecco 2003, Guirado et al. 2004), o que limita a aplicação de seus resultados às condições de campo, onde o desenvolvimento de insetos, fungos e bactérias ocorre naturalmente, sem que haja inoculação do agente causal, e de forma progressiva (Souza 1998).

Neste contexto, objetivou-se, com este trabalho, avaliar a eficácia da aplicação de caldas fertiprotetoras, em dois intervalos de aplicação, no controle de mancha-angular, em duas cultivares de feijoeiro comum, cultivadas sob irrigação por aspersão, em sistema orgânico.

\section{MATERIAL E MÉTODOS}

Dois experimentos foram desenvolvidos, um com a cultivar Pérola e o outro com a cultivar BRS Valente de feijão comum, no período de junho a setembro de 2006, na Fazenda Moça Terra, de propriedade da empresa Itec-Biotecnologia Agrícola Ltda., localizada no Núcleo Rural Santos Dumont (15'41'23,7'S, 47³4'18,5" W e 1.110 m de altitude), situado no Plano de Assentamento Dirigido do Distrito Federal (PAD-DF). O solo foi caracterizado como Latossolo Vermelho-Amarelo, com $52 \%$ de argila, $14 \%$ de silte e $34 \%$ de areia. A análise do solo da área experimental, à profundidade de 0,0-0,2 m, apresentou as seguintes características: $\mathrm{pH}$-água $=$ 5,$9 ; \mathrm{Al}=0,00 \mathrm{cmol}_{\mathrm{c}} \mathrm{dm}^{-3} ; \mathrm{K}=0,14 \mathrm{cmol}_{\mathrm{c}} \mathrm{dm}^{-3} ; \mathrm{Ca}=$ $3,06 \mathrm{cmol}_{\mathrm{c}} \mathrm{dm}^{-3} ; \mathrm{Mg}=1,31 \mathrm{cmol}_{\mathrm{c}} \mathrm{dm}^{-3} ; \mathrm{H}+\mathrm{Al}=$ $2,33 \mathrm{cmol}_{\mathrm{c}} \mathrm{dm}^{-3} ; \mathrm{P}=4,77 \mathrm{mg} \mathrm{dm}^{-3} ; \mathrm{Zn}=5,38 \mathrm{mgdm}^{-3}$; matéria orgânica $=2,35 \%$; e V $=66 \%$.

$\mathrm{O}$ delineamento experimental utilizado nos experimentos foi o de blocos ao acaso, em esquema fatorial $2 \times 4$, com quatro repetições, em que o primeiro fator correspondeu aos intervalos de aplicação e o segundo às caldas fertiprotetoras e à testemunha. Os tratamentos constituiram-se de dois intervalos de aplicação (de 15 em 15 dias e de 30 em 30 dias), a partir da emergência das plantas, totalizando seis e três aplicações, respectivamente, durante todo o ciclo da cultura, e de três tipos de caldas: calda bordalesa, calda sulfocálcica e calda elaborada com silicato $\left(\right.$ Rocksil $\left.^{\circledR}\right)$, além da testemunha sem aplicação de calda, totalizando 8 tratamentos. As parcelas foram constituídas de quatro linhas de $5 \mathrm{~m}$ de comprimento, com espaçamento de $0,5 \mathrm{~m}$ entre linhas, sendo consideradas as duas linhas centrais como área útil $\left(5 \mathrm{~m}^{2}\right)$.

O preparo do solo constou de uma gradagem niveladora, para controle de plantas espontâneas. Posteriormente, foram abertos, manualmente, os sulcos de plantio, onde foram aplicados, como adubação de base, $1.000 \mathrm{~kg} \mathrm{ha}^{-1}$ de composto orgânico farela- 
do $\left(0,7 \mathrm{~kg} \mathrm{ha}^{-1} \mathrm{~N} ; 34,2 \mathrm{~kg} \mathrm{ha}^{-1} \mathrm{P}_{2} \mathrm{O}_{5}\right.$; e 16,8 $\mathrm{kg} \mathrm{ha}^{-1}$ $\mathrm{K}_{2} \mathrm{O}$ ). A semeadura foi manual, distribuindo-se vinte sementes por metro. As sementes foram inoculadas com as estirpes PRF 81 (SEMIA 4080) e CIAT 899 (SEMIA 4077) de Rhizobium tropici.

Dez dias após a emergência, foi feito desbaste, para estande inicial de doze plantas por metro linear. O controle de plantas espontâneas foi realizado por meio de capina manual, aos trinta dias após a germinação. A adubação de cobertura foi feita utilizando-se composto orgânico farelado, na quantidade de $800 \mathrm{~kg} \mathrm{ha}^{-1}\left(0,6 \mathrm{~kg} \mathrm{ha}^{-1} \mathrm{~N} ; 27,4 \mathrm{~kg} \mathrm{ha}^{-1} \mathrm{P}_{2} \mathrm{O}_{5}\right.$; e $13,4 \mathrm{~kg} \mathrm{ha}^{-1} \mathrm{~K}_{2} \mathrm{O}$ ), logo após a capina.

As irrigações foram realizadas por aspersão, em sistema convencional fixo, utilizando-se aspersores de bocais em giro de $360^{\circ}$, de pressão média e alcance aproximado do jato de água em torno de 14 metros, espaçados de $12 \times 12$ metros. Antes do plantio, o perfil de $40 \mathrm{~cm}$ de solo foi preenchido com duas irrigações de $30 \mathrm{~mm}$. Após o plantio, foram feitas quatro irrigações, de dois em dois dias, com lâmina de 10-12 mm, para garantir o estabelecimento das culturas. A partir da emergência, o turno de rega e a lâmina foram determinados pelo Programa de Monitoramento de Irrigação da Embrapa Cerrados. As irrigações de cada variedade foram suspensas quando as vagens do terço médio das plantas atingiram a maturação fisiológica.

Para pulverização das plantas, utilizou-se pulverizador costal manual, com capacidade para 20 litros, pressão de trabalho de $300 \mathrm{kPA}$ (45 PSI), vazão de ponta a $45 \mathrm{PSI}=600 \mathrm{~mL} \mathrm{~min}^{-1}$ e volume de $400 \mathrm{~L} \mathrm{ha}^{-1}$ de calda, independentemente do tratamento, procedendo-se à limpeza do equipamento a cada troca de calda. Como espalhante adesivo, foi usado detergente neutro a $0,1 \%$. As caldas utilizadas foram: calda bordalesa a $1 \%$, preparada com $1 \mathrm{~kg}$ de cal virgem e $1 \mathrm{~kg}$ de sulfato de cobre, para 100 litros de água; calda sulfocálcica, preparada com 1,25 kg de cal virgem e 2,5 kg de enxofre em pó, para 10 litros de água, diluída para $2 \%$; e calda feita com silicato a $1 \%$, preparada com $1 \mathrm{~kg}$ de Rocksil ${ }^{\circledR}$, para 100 litros de água.

A severidade de mancha-angular foi avaliada aos 85 dias após a emergência (DAE), conforme sugerido por Sartorato \& Rava (2003), sendo estimada a percentagem de área foliar afetada pela doença em cada parcela, segundo escala diagramática definida por Sartorato (1989).

A colheita foi realizada aos $112 \mathrm{DAE}$, sendo colhidas as duas fileiras centrais de cada parcela, com trilha mecanizada. As variáveis analisadas foram: estande final, severidade de mancha-angular, peso médio de 100 grãos, produtividade de grãos, número de vagens por planta e número de grãos por vagem. $\mathrm{O}$ estande final foi obtido por meio da contagem de todas as plantas, nas duas linhas centrais das parcelas. O peso de 100 grãos, com umidade corrigida para $13 \%$, foi determinado utilizando-se a média de cinco amostras de 100 grãos por parcela. A produtividade de grãos, com umidade corrigida para $13 \%$, foi estimada em $\mathrm{kg} \mathrm{ha}^{-1}$, em função do rendimento de grãos, na área útil de cada parcela experimental. Foram retiradas, aleatoriamente, cinco plantas de cada parcela, para a determinação do número de vagens por planta e do número de grãos por vagem.

Para cálculo do custo da aplicação, foram computados os preços dos produtos utilizados para confecção de cada calda, o preço da mão de obra para aplicação e o custo da depreciação do equipamento. O lucro marginal bruto (LBmg) foi obtido por meio dos cálculos: $\Delta \mathrm{Q}=$ Rendimento do tratamento - Rendimento da testemunha; $\Delta \mathrm{Rmg}$ (receita marginal $)=$ $\Delta \mathrm{Q} \times$ preço do feijão $(\mathrm{kg}) ; \Delta \mathrm{Cmg}$ (custo marginal) $=$ Custo total de aplicação da calda, durante o ciclo da cultura; e LBmg (lucro bruto marginal ) $=\Delta \mathrm{Rmg}$ $\Delta \mathrm{Cmg}$. Todos os dados foram transformados para aplicação em um hectare.

As análises estatísticas foram feitas por meio do programa computacional Sisvar (Ferreira 2000). As médias foram comparadas pelo teste de Scott-Knott, a 5\% (Scott \& Knott 1974). A correlação entre as variáveis analisadas foi obtida pelo teste de Pearson.

\section{RESULTADOS E DISCUSSÃO}

\section{Cultivar Pérola}

Houve interação significativa entre os intervalos de aplicação e os tipos de caldas, indicando que as condições específicas, nos dois intervalos estudados, influíram, diferentemente, no número médio de grãos por vagem e na severidade de mancha-angular (Tabela 1). Para o rendimento de grãos, estande final, peso de 100 grãos, número médio de vagens por planta e eficácia de controle, não houve interação dos fatores avaliados.

A severidade da doença diminuiu o estande final, o número de vagens por planta e o rendimento de grãos, sendo que a utilização das caldas aumentou a 
Tabela 1. Quadrados médios da análise de variância, média $\left(\mathrm{kg} \mathrm{ha}^{-1}\right)$ e coeficiente de variação do rendimento de grãos $\left(\mathrm{kg}\right.$ ha $\left.{ }^{-1}\right)$, estande final (plantas por metro linear), peso de 100 grãos (g), número de vagens por planta, número de grãos por vagem, incidência de mancha-angular e eficácia de controle de três tipos de caldas fertiprotetoras, aplicadas às cultivares de feijoeiro comum Pérola e BRS Valente, sob irrigação e em sistema orgânico de produção (Núcleo Rural Santos Dumont, DF, 2006).

\begin{tabular}{lccccccc}
\hline & Rendimento & $\begin{array}{c}\text { Estande } \\
\text { final }\end{array}$ & $\begin{array}{c}\text { Peso de } \\
100 \text { grãos }\end{array}$ & $\begin{array}{c}\text { Vagens } \\
\text { por planta }\end{array}$ & $\begin{array}{c}\text { Grãos } \\
\text { por vagem }\end{array}$ & $\begin{array}{c}\text { Severidade } \\
\text { mancha-angular }\end{array}$ & $\begin{array}{c}\text { Eficiência } \\
\text { de controle }\end{array}$ \\
\hline Blocos $^{1}$ & 175426,42 & 0,27 & 4,55 & 1,45 & 0,04 & 79,12 & 65,58 \\
Intervalos (I) & $32640,13^{\text {ns }}$ & $0,12^{\text {ns }}$ & $2,97^{\text {ns }}$ & $0,28^{\text {ns }}$ & $0,95^{*}$ & $312,50^{\text {ns }}$ & $480,50^{\text {ns }}$ \\
Caldas (C) & $386860,42^{*}$ & $0,10^{\text {ns }}$ & $3,99^{\text {ns }}$ & $0,61^{\text {ns }}$ & $1,32^{* *}$ & $8479,17 * *$ & $13661,50^{* *}$ \\
I X C & $38162,38^{\text {ns }}$ & $0,26^{\text {ns }}$ & $3,03^{\text {ns }}$ & $1,20^{\text {ns }}$ & $1,17^{* *}$ & $512,50^{*}$ & $748,17^{\text {ns }}$ \\
Resíduo & 95324,68 & 0,85 & 2,69 & 1,78 & 0,18 & 155,36 & 324,63 \\
Média & 3081 & 9,73 & 29,10 & 11,78 & 4,68 & 49,38 & 11,41 \\
CV(\%) & 10,02 & 9,48 & 5,64 & 11,33 & 9,09 & 25,24 & 30,42 \\
\hline Blocos & 479739,21 & 0,29 & 2,40 & 13,79 & 0,12 & 45,83 & 419,11 \\
I & $119008,00^{* *}$ & $1,49^{\text {ns }}$ & $7,70^{*}$ & $4,50^{\text {ns }}$ & $0,18^{\text {ns }}$ & $2812,50^{* *}$ & $7230,03^{* *}$ \\
C & $513914,88^{* *}$ & $2,42^{\text {ns }}$ & $13,60^{* *}$ & $3,37^{\text {ns }}$ & $2,244^{* *}$ & $1945,83^{* *}$ & $3013,69^{* *}$ \\
I X C & $160237,25^{\text {ns }}$ & $0,71^{\text {ns }}$ & $0,75^{\text {ns }}$ & $4,75^{\text {ns }}$ & $0,11^{\text {ns }}$ & $812,50^{* *}$ & $1350,11^{* *}$ \\
Resíduo & 93516,71 & 1,18 & 1,61 & 4,79 & 0,27 & 112,50 & 273,90 \\
Média & 2533 & 9,74 & 23,82 & 12,31 & 4,36 & 60,62 & 20,69 \\
CV(\%) & 12,07 & 11,13 & 5,32 & 17,78 & 11,92 & 17,50 & 27,64 \\
\hline
\end{tabular}

***: significativo a $5 \%$ e $1 \%$, respectivamente, pelo teste $\mathrm{F} ;{ }^{\text {ns: }}$ não-significativo; ${ }^{1}$ Pérola; ${ }^{2}$ BRS Valente.

eficácia de controle da doença (Tabela 2). No entanto, somente a calda bordalesa proporcionou acréscimo significativo ao rendimento de grãos, em relação à testemunha e às demais caldas testadas (Tabela 3), propiciando rentabilidade de $\mathrm{R} \$ 386,40$ por hectare, quando aplicada quinzenalmente, embora o intervalo de aplicação não tenha afetado o rendimento de grãos (Tabela 4).
O estande final, com valores entre 9,6 e 9,9 plantas por metro linear, não foi influenciado pelo emprego das caldas, nem pelos dois intervalos de aplicação (Tabela 1), havendo, entretanto, correlação negativa entre esta variável e a severidade do ataque de mancha-angular e correlação positiva entre esta variável e a eficácia do controle da doença (Tabela 2). O peso médio de 100 grãos, com valores entre $29,0 \mathrm{~g}$

Tabela 2. Valores $r$ de correlação de Pearson ${ }^{1}$ entre características agronômicas e produtivas de duas cultivares de feijoeiro comum irrigado, submetidas a três tipos de caldas fertiprotetoras, em sistema orgânico de produção (Núcleo Rural Santos Dumont, DF, 2006).

\begin{tabular}{lccccccc}
\hline \multicolumn{1}{c}{ Variáveis } & $\mathrm{R}$ & $\mathrm{EF}$ & $\mathrm{NV}$ & $\mathrm{GV}$ & $\mathrm{P} 100$ & $\mathrm{SM}$ & $\mathrm{EC}$ \\
\hline $\mathrm{RE}$ & - & $0,69^{\mathrm{ns}}$ & $0,98^{* *}$ & $0,09^{\mathrm{ns}}$ & $0,27^{\mathrm{ns}}$ & $-0,89^{*}$ & $0,89^{*}$ \\
$\mathrm{EF}$ & $0,09^{\mathrm{ns}}$ & - & $0,80^{\mathrm{ns}}$ & $0,12^{\mathrm{ns}}$ & $0,01^{\mathrm{ns}}$ & $-0,90^{*}$ & $0,90^{*}$ \\
$\mathrm{NV}$ & $0,87^{\mathrm{ns}}$ & $-0,40^{\mathrm{ns}}$ & - & $-0,01^{\mathrm{ns}}$ & $-0,31^{\mathrm{ns}}$ & $-0,96^{*}$ & $0,96^{*}$ \\
GV & $0,97^{*}$ & $-0,01^{\mathrm{ns}}$ & $0,92^{*}$ & - & $-0,92^{*}$ & $0,11^{\mathrm{ns}}$ & $-0,13^{\mathrm{ns}}$ \\
P100 & $0,80^{\mathrm{ns}}$ & $0,51^{\mathrm{ns}}$ & $-0,99^{* *}$ & $0,86^{\mathrm{ns}}$ & - & $-0,35^{\mathrm{ns}}$ & $0,37^{\mathrm{ns}}$ \\
SM & $-0,96^{*}$ & $0,14^{\mathrm{ns}}$ & $-0,96^{*}$ & $-0,99^{* *}$ & $-0,92^{*}$ & - & - \\
EC & $0,94^{*}$ & $-0,16^{\mathrm{ns}}$ & $0,96^{*}$ & $0,99^{*}$ & $0,92^{*}$ & - & - \\
\hline
\end{tabular}

${ }^{1}$ Cultivar Pérola diagonal superior, cultivar BRS Valente diagonal inferior; ${ }^{\text {ns: }}$ não significativo ; *, **: significativo a $5 \%$ e $1 \%$, respectivamente; $\mathrm{R}=$ rendimento; EF $=$ estande final; $\mathrm{NV}=$ número de vagens; $\mathrm{GV}=$ grãos por vagem; $\mathrm{P} 100=$ peso de 100 grãos; $\mathrm{SM}$ = severidade da mancha-angular; EC = eficácia de controle.

Tabela 3. Rendimento de grãos $\left(\mathrm{kg} \mathrm{ha}^{-1}\right)$, rendimento relativo (\%), eficácia de controle (\%) e desdobramento das interações significativas da análise de variância, referentes ao número de grãos por vagem e severidade do ataque de mancha-angular (\%) da cultivar de feijoeiro comum Pérola, sob irrigação e submetida à aplicação de três tipos de caldas fertiprotetoras, em sistema orgânico de produção (Núcleo Rural Santos Dumont, DF, 2006).

\begin{tabular}{|c|c|c|c|c|c|c|c|}
\hline \multirow{2}{*}{ Tipos de calda } & \multirow{2}{*}{$\mathrm{R}$} & \multirow{2}{*}{ RR } & \multirow{2}{*}{$\mathrm{EC}$} & \multicolumn{2}{|c|}{ GV } & \multicolumn{2}{|c|}{ SMA } \\
\hline & & & & 15 dias & 30 dias & 15 dias & 30 dias \\
\hline Bordalesa & $3370 a^{*}$ & 118 & $75 \mathrm{a}$ & 4,48 aA & 4,93 bA & $20 \mathrm{bA}$ & $20 \mathrm{cA}$ \\
\hline Sulfocálcica & $3122 \mathrm{~b}$ & 109 & $72 \mathrm{a}$ & 4,48 aA & $4,65 \mathrm{bA}$ & $20 \mathrm{bA}$ & $25 \mathrm{cA}$ \\
\hline Rocksil $^{\circledR}$ & 2967 b & 104 & $4 \mathrm{~b}$ & $4,58 \mathrm{aB}$ & $5,87 \mathrm{aA}$ & $90 \mathrm{aA}$ & $60 \mathrm{bB}$ \\
\hline Testemunha & $2864 \mathrm{~b}$ & 100 & $0 \mathrm{~b}$ & $4,53 \mathrm{aA}$ & $3,98 \mathrm{cA}$ & $80 \mathrm{aA}$ & $80 \mathrm{aA}$ \\
\hline
\end{tabular}

* Médias seguidas da mesma letra minúscula, na coluna, e maiúscula, na linha, não diferem, estatisticamente, pelo teste de Scott Knott, a 5\%; R = rendimento; RR = rendimento relativo; $\mathrm{EC}=$ eficácia relativa; $\mathrm{GV}=$ grãos por vagem; $\mathrm{SMA}=$ severidade da mancha-angular. 
Tabela 4. Valores por hectare de custo de uma aplicação, custo marginal $(\Delta \mathrm{Cmg}) *$ e lucro bruto marginal (LBmg), de três tipos de caldas fertiprotetoras aplicadas a cultivares de feijoeiro comum Pérola e BRS Valente, sob irrigação, em sistema orgânico de produção (Núcleo Rural Santos Dumont, DF, 2006).

\begin{tabular}{|c|c|c|c|c|c|c|c|c|}
\hline \multirow{2}{*}{ Tipo e periodicidade } & \multirow{2}{*}{ Custo (R\$) } & \multicolumn{2}{|c|}{$\Delta \mathrm{Rmg}(\mathrm{R} \$)$} & \multirow{2}{*}{$\Delta \mathrm{Cmg}(\mathrm{R} \$)$} & \multicolumn{2}{|c|}{ LBmg (R\$) } & \multicolumn{2}{|c|}{ Lucro relativo (\%) } \\
\hline & & Pérola & BRS Valente & & Pérola & BRS Valente & Pérola & BRS Valente \\
\hline Bordalesa 15 dias & 45,60 & 660,00 & 846,75 & 273,60 & 386,40 & 573,15 & 100,00 & 100,00 \\
\hline Sulfocálcica 15 dias & 18,90 & 312,50 & 577,50 & 113,40 & 199,10 & 464,10 & 51,53 & 80,97 \\
\hline Rocksil $^{\circledR} 15$ dias & 34,00 & 120,25 & 495,00 & 204,00 & $-83,75$ & 291,00 & $-21,67$ & 50,77 \\
\hline Testemunha 15 dias & 0,00 & 0,00 & 0,00 & 0,00 & 0,00 & 0,00 & 0,00 & 0,00 \\
\hline Bordalesa 30 dias & 45,60 & 351,00 & 260,50 & 136,80 & 214,20 & 123,70 & 55,44 & 21,58 \\
\hline Sulfocálcica 30 dias & 18,90 & 203,25 & 387,00 & 56,70 & 146,55 & 330,30 & 37,93 & 57,63 \\
\hline Rocksil $^{\circledR} 30$ dias & 34,00 & 85,00 & $-50,25$ & 102,00 & $-17,00$ & $-152,25$ & $-4,40$ & $-26,56$ \\
\hline Testemunha 30 dias & 0,00 & 0,00 & 0,00 & 0,00 & 0,00 & 0,00 & 0,00 & 0,00 \\
\hline
\end{tabular}

* Calculado com o preço do feijão a R\$ 60,00/saca, em outubro de 2004 (Conab 2008).

e 30,7 g, e o número médio de vagens por planta, com valores entre 11,5 e 12,1, não foram influenciados pelo emprego das caldas, nem pelos intervalos de aplicação (Tabela 1). Entretanto, observou-se correlação negativa entre o número médio de vagens por planta e a severidade de mancha-angular, e correlação positiva entre esta variável e a eficácia do controle da doença (Tabela 2).

O número médio de grãos por vagem não foi influenciado pelos tipos de caldas, quando o intervalo de aplicação foi quinzenal. Quando o intervalo foi mensal, a calda feita com Rocksil ${ }^{\circledR}$ proporcionou aumento na média deste componente, quando comparada com as outras caldas e com a testemunha (Tabela 3). O aumento do número médio de grãos por vagem causou a diminuição do peso de 100 grãos (Tabela 2). Segundo Costa et al. (1983), a variação dos componentes da produção do feijoeiro colabora com a manutenção da estabilidade da produtividade de grãos, ou seja, no caso de um destes componentes ser prejudicado por qualquer fator, outro componente se eleva, estabilizando a produtividade.

Nos tratamentos pulverizados com as caldas bordalesa e sulfocálcica, a severidade da mancha-angular foi menor e foi maior a eficácia de controle, quando comparados com a testemunha e o tratamento pulverizado com calda contendo Rocksil ${ }^{\circledR}$ (Tabela 3). O intervalo de aplicação não proporcionou diferença na severidade da doença (Tabela 1).

A cultivar Pérola é, atualmente, a mais plantada na região do Distrito Federal (Sousa 2002), tendo maior disponibilidade de sementes e procura no mercado consumidor, tanto orgânico quanto convencional. Entretanto, seu plantio tem sido reduzido, devido à alta susceptibilidade a doenças que a cultivar apresenta, dentre elas a mancha-angular. Os resultados deste trabalho evidenciam que os prejuízos ocasionados pela doença podem ser reduzidos pela utilização da calda bordaleza, em sistema orgânico de produção no inverno e sob irrigação por aspersão.

Resultados semelhantes foram obtidos por Souza (1998), que testou dois tipos de calda e um biofertilizante, para o controle de requeima (Phytophtora infestans) da batata, e constatou aumento no rendimento, utilizando-se calda bordalesa. Na cultura do alho, Souza (1998) testou três tipos de calda, um biofertilizante e um extrato, no controle de Alternaria porri, e, também, observou maior rendimento, utilizando-se este tipo de calda. Segundo o autor, o aumento no rendimento das culturas pode ser explicado não só pela eficácia no controle das doenças, mas, também, pela ação benéfica que exerce sobre o metabolismo das plantas, aumentando a proteossíntese, principalmente pela oferta de micronutrientes.

\section{Cultivar BRS Valente}

Ao contrário da cultivar Pérola, a cultivar BRS Valente apresenta reação intermediária ao ataque de doenças, principalmente antracnose, em condições artificiais, e mancha-angular, em condições de campo (Del Peloso et al. 2004), sendo esta a razão de sua escolha.

Não houve interação entre os intervalos de aplicação e os tipos de calda, para as variáveis rendimento, estande final, peso de 100 grãos, número de vagens por planta e número de grãos por vagem (Tabela 1). Houve interação dos intervalos de aplicação com os tipos de caldas aplicadas, para a severidade de mancha-angular e para a eficácia 
Tabela 5. Rendimento de grãos $\left(\mathrm{kg} \mathrm{ha}^{-1}\right)$, rendimento relativo (\%), peso de 100 grãos $(\mathrm{g})$, número de grãos por vagem e desdobramento das interações significativas da análise de variância referente à severidade de mancha-angular (\%) e eficácia de controle (\%), de três tipos de caldas fertiprotetoras aplicadas à cultivar de feijoeiro comum BRS Valente, sob irrigação, em sistema orgânico de produção (Núcleo Rural Santos Dumont, DF, 2006).

\begin{tabular}{|c|c|c|c|c|c|c|c|c|}
\hline \multirow{2}{*}{ Tratamentos } & \multirow{2}{*}{$\mathrm{R}$} & \multirow{2}{*}{$\mathrm{RR}$} & \multirow{2}{*}{ P100 } & \multirow{2}{*}{ GV } & \multicolumn{2}{|c|}{ SMA } & \multicolumn{2}{|c|}{$\mathrm{EC}$} \\
\hline & & & & & 15 dias & 30 dias & 15 dias & 30 dias \\
\hline Bordalesa & $2772 a^{*}$ & 125 & $23,98 \mathrm{~b}$ & $4,80 \mathrm{a}$ & $30 \mathrm{bB}$ & $70 \mathrm{aA}$ & $62 \mathrm{aA}$ & $4 \mathrm{aB}$ \\
\hline Sulfocálcica & $2701 \mathrm{a}$ & 122 & $25,56 \mathrm{a}$ & $4,83 \mathrm{a}$ & $30 \mathrm{bB}$ & $60 \mathrm{aA}$ & $62 \mathrm{aA}$ & $18 \mathrm{aB}$ \\
\hline Rocksil $^{\circledR}$ & $2441 \mathrm{~b}$ & 110 & $23,28 \mathrm{~b}$ & $3,96 \mathrm{~b}$ & $65 \mathrm{bA}$ & $75 \mathrm{aA}$ & $17 \mathrm{bA}$ & $-2 \mathrm{aA}^{1}$ \\
\hline Testemunha & $2218 b$ & 100 & $22,50 \mathrm{~b}$ & $3,84 \mathrm{~b}$ & $80 \mathrm{aA}$ & $75 \mathrm{aA}$ & $0 \mathrm{bA}$ & $0 \mathrm{aA}$ \\
\hline
\end{tabular}

* Médias seguidas da mesma letra minúscula, na coluna, e maiúscula, na linha, não diferem, estatisticamente, pelo teste de Scott Knott, a $5 \%$; ${ }^{1}$ Nota negativa significa eficácia de controle abaixo da testemunha; $\mathrm{R}=$ rendimento; $\mathrm{RE}=$ rendimento relativo; $\mathrm{P} 100=$ peso de 100 grãos; $\mathrm{SMA}=$ severidade da mancha-angular; $\mathrm{EC}=$ eficácia de controle.

de seu controle, demonstrando que as condições específicas, nos dois intervalos estudados, influíram, diferentemente, nestas variáveis.

A severidade de mancha-angular diminuiu o rendimento de grãos e os diferentes tipos de caldas aumentaram a eficácia do controle da doença (Tabela 2). As caldas bordalesa e sulfocálcica, quando aplicadas quinzenalmente, diminuíram a severidade e aumentaram a eficácia de seu controle, proporcionando acréscimo significativo ao rendimento $(25 \%$ e $22 \%$, respectivamente), em relação à testemunha e à calda elaborada com Rocksil ${ }^{\circledR}$ (Tabela 5). Quando aplicadas mensalmente, as caldas não tiveram efeito sobre a severidade da mancha-angular e eficácia de controle da doença.

Quando calculados o custo da aplicação das caldas, durante o ciclo da cultura, e o respectivo lucro que cada uma proporcionou, em razão do seu intervalo de aplicação e do aumento no rendimento (lucro bruto marginal), observou-se que a calda bordalesa, seguida pela calda sulfocálcica, quando aplicadas quinzenalmente, proporcionaram lucro de $\mathrm{R} \$ 573,15 \mathrm{ha}^{-1}$ e R $\$ 464,10 \mathrm{ha}^{-1}$, respectivamente (Tabela 4). Assim, a calda bordalesa e a calda sulfocálcica, aplicadas quinzenalmente, podem ser indicadas para o controle de mancha-angular na cultivar BRS Valente, em sistema orgânico de produção no inverno e sob irrigação por aspersão.

O estande final, com valores entre 9,1 e 10,4 plantas por metro linear, não foi influenciado pelas caldas, nem pelos intervalos de aplicação (Tabela 1). Para o peso médio de 100 grãos, houve diferença entre os intervalos de aplicação das caldas (Tabela 1), sendo que a aplicação quinzenal $(24,32 \mathrm{~g})$ proporcionou valor superior à aplicação mensal $(23,45 \mathrm{~g})$. Entre as caldas testadas, somente a calda sulfocálcica proporcionou aumento desta variável (Tabela 5). O número médio de vagens por planta, com valores entre 11,6 e 13,1, não foi influenciado pelo emprego das caldas, nem pelos intervalos de aplicação (Tabela 1), havendo, entretanto, correlação negativa entre esta variável e a severidade de mancha-angular, e correlação positiva entre esta variável e a eficácia do controle da doença (Tabela 2). O estudo de correlação mostrou, ainda, diminuição do peso médio de 100 grãos, em função do aumento do número médio de vagens por planta (Tabela 2), corroborando o estudo realizado por Carvalho \& Wanderley (2007). O uso das caldas sulfocálcica e bordalesa aumentou o número médio de grãos por vagem (Tabela 5), não havendo, entretanto, influência dos dois intervalos de aplicação (Tabela 1).

No presente experimento, não foi constatada fitotoxidade nas plantas de feijoeiro, em relação às caldas testadas. Durante o ciclo da cultura, foram feitos levantamentos da população de pragas, não se constatando níveis de dano econômico que justificassem seu controle, nem influência das caldas nas respectivas populações.

\section{CONCLUSÕES}

1. A calda bordalesa pode ser indicada para o controle de mancha-angular, na cultivar de feijoeiro comum Pérola (grupo carioca), em sistema orgânico de produção no inverno e sob irrigação por aspersão.

2. A calda bordalesa e a calda sulfocálcica, aplicadas quinzenalmente, podem ser indicadas para o controle de mancha-angular na cultivar de feijoeiro comum BRS Valente (grupo preto), em sistema orgânico de produção no inverno e sob irrigação por aspersão. 


\section{REFERÊNCIAS}

ABREU JÚNIOR, H. de. Utilização de defensivos naturais na fruticultura tropical. Juazeiro: Fenagri, 2003.

AGRIOS, G. N. Plant pathology. 4. ed. San Diego: Academic Press, 1997.

ALTIERI, M. A. The ecological role of biodiversity in agroecosystems. Agriculture, Ecosystems \& Environment, Amsterdam, v. 74, n. 1, p. 19-31, 1999.

CARVALHO, W. P.; WANDERLEY, A. Avaliação de cultivares de feijão comum para o plantio em sistema orgânico no Cerrado, ciclo 2004/2005. Bioscience Journal, Uberlândia, v. 23, n. 13, p. 50-59, 2007.

COMPANHIA NACIONAL DE ABASTECIMENTO (Conab). Preços médios de mercado. 2008. Disponível em: $<$ http://www.conab.gov.br/cgi-bin/htsearch $>$. Acesso em: 12 dez. 2008.

COSTA, J. G. C.; KOHASHI-SHIBATA, J.; COLIN, S. M. Plasticidade no feijoeiro comum. Pesquisa Agropecuária Brasileira, Brasília, DF, v. 18, n. 5, p. 159-167, 1983.

DEL PELOSO, M. J. et al. BRS Valente: black common bean. Crop Breeding and Applied Biotechnology, Viçosa, v. 4, n. 1, p. 258-260, 2004.

FERREIRA, D. F. Manual do sistema Sisvar para análises estatísticas. Lavras: UFLa, 2000.

GUIRADO, N. et al. Controle de pragas e doenças em sistemas de cultivo orgânico. In: ISHIMURA, I. Manual de agricultura orgânica. Piracicaba: JICA, 2004. p. 122-136.

INNECCO, R. Efeito de óleos essenciais de plantas medicinais como defensivo agrícola. Fitopatologia Brasileira, Lavras, v. 28, supl., p. 57-59, 2003.

JESUS JUNIOR, W. C. et al. Relationships between angular leaf spot, healthy leaf area, effective leaf area and yield of Phaseolus vulgaris. European Journal of Plant Pathology, New York, v. 109, n. 3, p. 625-632, 2003.

MAFFIA, L. A.; MIZUBUTI, E. S. G. Fitopatologia $x$ sociedade. Ação Ambiental, Viçosa, v. 2, n. 1, p. 9-12, 1999.

MIZUBUTI, E. S. G.; MAFFIA, L. A. Aplicações de princípios de controle no manejo ecológico de doenças de plantas. Informe Agropecuário, Belo Horizonte, v. 22, n. 212, p. 9-18, 2001.

PENTEADO, S. R. Controle alternativo de pragas e doenças com as caldas bordalesa, sulfocálcica e viçosa. Campinas: Bueno Mendes, 2000.
RAVA, C. A. Eficiência de fungicidas no controle da antracnose e da mancha angular do feijoeiro comum. Summa Phytopathologica, Botucatu, v. 28, n. 1, p. 65-69, 2002.

REIS-PRADO, F. G. et al. Reação de cultivares de feijoeiro comum à mancha angular em casa de vegetação. Fitopatologia Brasileira, Lavras, v. 31, n. 2, p. 306-309, 2006.

RODRIGUES, G. B. et al. Desempenho de cultivares de cebola nos sistemas orgânico e convencional em Minas Gerais. Horticultura Brasileira, Campinas, v. 24, n. 2, p. 206-209, 2006.

ROMBALDI, C. V. et al. Produtividade e qualidade de uva, cv. Isabel, em dois sistemas de produção. Revista Brasileira de Fruticultura, Jaboticabal, v. 26, n. 1, p. 8991, 2004.

SARTORATO, A. Resistência vertical e horizontal do feijoeiro comum (Phaseolus vulgaris L.) a Isariopsis griseola Sacc. 1989. 131 f. Tese (Doutorado em Fitopatologia)-Escola Superior de Agricultura "Luiz de Queiroz", Universidade de São Paulo, Piracicaba, 1989.

SARTORATO, A.; RAVA, C. A. Controle químico da mancha angular do feijoeiro comum. Summa Phytopathologica, Botucatu, v. 29, n. 2, p. 202-204, 2003.

SARTORATO, A.; RAVA, C. A. Influência da cultivar e do número de inoculações na severidade da mancha angular (Isariopsis griseola) e nas perdas na produção do feijoeiro comum (Phaseolus vulgaris). Fitopatologia Brasileira, Lavras, v. 17, n. 2, p. 247-251, 1992.

SCHWAN-ESTRADA, K.; STANGARLIN, J.; CRUZ, M. Uso de extratos vegetais no controle de fungos fitopatogênicos. Revista Floresta, Curitiba, v. 30, n. 1, p. 129-137, 2000.

SCOTT, A. J.; KNOTT, M. A cluster analysis method for grouping means in the analysis of variants. Biometric, Arlington, v. 30, n. 3, p. 507-512, 1974.

SOUSA, J. B. de. Conjuntura rural do Distrito Federal. Brasília, DF: Emater-DF, 2002.

SOUZA, J. L. de. Agricultura orgânica: tecnologias para a produção de alimentos saudáveis. Vitória: Emcapa, 1998.

SOUZA, J. L. de. Manual de horticultura orgânica. 2. ed. Viçosa: Aprenda Fácil, 2006. 